\title{
Involvement of endogenous glucagon-like peptide-1(7-36) amide on glycaemia-lowering effect of oligofructose in streptozotocin-treated rats
}

\author{
Patrice D Cani*, Catherine A Daubioul*, Brigitte Reusens ${ }^{1}$, \\ Claude Remacle ${ }^{1}$, Grégory Catillon and Nathalie M Delzenne \\ Unit of Pharmacokinetics, Metabolism, Nutrition and Toxicology, Université catholique de Louvain, Brussels, Belgium \\ ${ }^{1}$ Unit of Animal Biology, Université catholique de Louvain, Brussels, Belgium \\ (Requests for offprints should be addressed to N M Delzenne, UCL-PMNT 7369, 73 Avenue Mounier, B-1200 Brussels, Belgium; \\ Email: delzenne@pmnt.ucl.ac.be) \\ *(P D Cani and C A Daubioul contributed equally to this work)
}

\begin{abstract}
We have evaluated the influence of oligofructose (OFS), a fermentable dietary fibre, on glucose homeostasis, insulin production and intestinal glucagon-like peptide-1 (GLP-1) in streptozotocin-treated diabetic rats.

Male Wistar rats received either i.v. streptozotocin (STZ; $40 \mathrm{mg} / \mathrm{kg}$ ) or vehicle (CT); one week later, they were fed for 6 weeks with either the standard diet (STZ-CT), or with a diet containing 10\% oligofructose (STZ-OFS); both diets were available ad libitum. In a second set of experiments (duration 4 weeks), a supplemental group of food-restricted rats (STZ-Res) receiving a similar intake as CT rats, was added.

OFS improved glucose tolerance and reduced food intake as compared with STZ-CT rats in both the post-prandial state and after an oral glucose tolerance test.
\end{abstract}

After 6 weeks, portal and pancreatic insulin concentrations were doubled in STZ-OFS rats. Food restriction improved these parameters when compared with STZ-CT rats, but to a lesser extent than in the STZ-OFS group. We have shown that OFS treatment increased portal and colonic GLP-1(7-36) amide levels and doubled colonic proglucagon and prohormone convertase 1 mRNA levels; both OFS and food restriction lowered ileal GLP-1(7-36) amide levels as compared with levels in STZ-CT rats.

We propose that OFS, through its fermentation in the colon, promotes the expression and secretion of colonic peptides, namely GLP-1(7-36) amide, with beneficial consequences on glycaemia, insulin secretion and hyperphagia in diabetic rats.

Journal of Endocrinology (2005) 185, 457-465

\section{Introduction}

Dietary fibres are often cited as food components susceptible to lower fasting and post-prandial plasma glucose concentrations, and are proposed as key nutrients in the control of glycaemia in diabetic patients (Roberfroid \& Delzenne 1998, Jenkins et al. 1999). Soluble dietary fibres, such as guar gum, pectin, or mucilages, reduce postprandial glycaemia by delaying gastric emptying through their gel-forming effect (Nuttall 1993). But there are other dietary fibres which do not exhibit gel forming properties which seem to be promising in the control of metabolic disorders associated with glucose intolerance and obesity. This is the case with dietary fructans, which are commonly found in several vegetables and cereals (onion, garlic, wheat etc.) and in food products in which they are added for their nutritional or organoleptic properties (fat or sugar replacer) (Roberfroid \& Delzenne 1998). Fructans are mainly known as prebiotics, meaning that, through their fermentation in the caeco-colon, they selectively stimulate lactic acid-producing bacteria. These bacteria produce short chain fatty acids (SCFA) involved in the modulation of gut physiological functions (immunity, cell proliferation, mineral absorption etc.) (Delzenne 2003, Delzenne et al. 2003). We have shown in previous studies that oligofructose - a short chain fructan obtained from inulin decreases steatosis by reducing spontaneous food intake in obese Zucker $\mathrm{Fa} / \mathrm{Fa}$ rats (Daubioul et al. 2002). Oligofructose also decreases the glucose/insulin ratio in high fructose-fed rats, suggesting an improved beta-cell glucose sensitivity (Busserolles et al. 2003). We have also demonstrated that a lower post-prandial glycaemia in oligofructose-fed rats could participate in decreased lipogenesis and triacylglycerol-very low density lipoprotein (TG-VLDL) secretion (Kok et al. 1998a, Delzenne \& Williams 2002). The fermentation products of dietary fibres have been shown to increase proglucagon mRNA in the colon (Reimer \& McBurney 1996, Cani et al. 2004). 
In the intestine, the post-translational modification of the proglucagon gene by prohormone convertase 1 (PC1) leads to the production of glucagon-like peptide-1(7-36) amide (GLP-1(7-36) amide) which, among its pleiotrophic effects, participates in pancreatic beta cell proliferation and neogenesis and is also involved in the control of food intake (Orskov et al. 1989, Domon-Dell et al. 2002, Drucker 2002). The modulation of glucose tolerance by oligofructose in hyperglycaemia/hypoinsulinemia has never been related to its efficiency to modify endogenous GLP-1(7-36) amide production. Therefore, the aims were to study (1) the effect of oligofructose on glucose tolerance and insulin production and (2) to evaluate GLP-1(7-36) amide production in streptozotocin-treated diabetic rats.

\section{Materials and Methods}

\section{Animals and diets}

Rats received care in compliance with the institution's guidelines from the National Academy of Sciences (NIH publication 86-23; http://www.nih.gov). All animal experiments were approved by the local committee and the housing conditions were as specified by the Belgian Law of November 141993 on the protection of laboratory animals (agreement no. LA 1230315).

In all experiments, 8 -week-old male Wistar rats weighing 220-250 g were obtained from Harlan (Horst, The Netherlands) and were housed in a temperature- and humidity-controlled room with a $12 \mathrm{~h}$ light/12 h darkness cycle. Animals were housed and acclimated in individual wire mesh-bottomed cages. Rats were acclimated for 7 days, and were given free access to a powdered A04 standard diet (A04, UAR, Villemoisson-sur-Orge, France) and water before the experimental period. The diet was removed at $0900 \mathrm{~h}$ and streptozotocin (STZ) (Sigma, St Louis, MI, USA) (40 mg/kg body weight) or the same volume of vehicle (citrate buffer $0 \cdot 1 \mathrm{M} \mathrm{pH} \mathrm{4.5)} \mathrm{was} \mathrm{injected} \mathrm{into} \mathrm{the}$ caudal vein of rats ( $n=10$ per group) during the afternoon.

Rats then received the standard diet and tap water ad libitum for one week. One week after STZ injection, only rats with post-prandial glycaemia between $15 \mathrm{mM}$ and $35 \mathrm{mM}$ were kept for the experiment (remaining animals $n=5$ per group), and these were randomised in order to get the same mean glycaemia in all groups before nutritional treatment.

In a first experiment, rats were fed either the standard diet (STZ-CT) or the oligofructose diet (STZ-OFS), prepared by mixing $900 \mathrm{~g}$ standard diet with $100 \mathrm{~g}$ Raftilose P95 (ORAFTI, Tienen, Belgium; Raftilose P95 consisted of a mix of fructooligosaccharides with a number of fructosyl moeities from 2 to 7). Both diets were available ad libitum. All animals were killed after 6 weeks $(n=5$ per group).

In a second experiment, an additional group was added (STZ-Res), consisting of streptozotocin-treated diabetic animals food-restricted in order to receive the same amount of diet as the non-diabetic rats (CT). All the animals ( $n=5$ per group) were killed after 4 weeks. In all experiments, food intake and body weight were monitored twice a week.

\section{Blood and tissue samples}

An oral glucose tolerance test (gavage with $2 \mathrm{~g}$ glucose $/ \mathrm{kg}$ body weight) was performed after 4 weeks of treatment (experiment 1) in rats previously fasted for at least $18 \mathrm{~h}$, and blood was sampled at 0, 15, 30, 120 and $180 \mathrm{~min}$ for glucose and insulin measurement.

During the treatment, blood samples were taken from the tail vein in EDTA tubes (Sarstedt, Nümbrecht, Germany), and the plasma obtained by centrifugation was stored at $-20{ }^{\circ} \mathrm{C}$. At the end of the experiment, rats were anaesthetised by intra-peritoneal injection of pentobarbital $(60 \mathrm{mg} / \mathrm{kg}$ body weight, Nembutal, Sanofi Santé Animale Benelux, Brussels, Belgium), and portal vein blood samples were collected in EDTA tubes containing dipeptidyl peptidase IV inhibitor $(10 \mu \mathrm{l} / \mathrm{ml})$ (DPPIV inhibitor, Linco Research, St Charles, MI, USA); after centrifugation, plasma was stored at $-80{ }^{\circ} \mathrm{C}$.

Segments of distal ileon $(4 \mathrm{~cm}$ of intestine taken above the junction with the caecum), and colon corresponding to segments taken between the caecal junction and the rectum, were immediately excised, flushed with ice-cold saline, immersed in liquid nitrogen, and stored at $-80{ }^{\circ} \mathrm{C}$ for further mRNA and peptides analysis.

\section{Pancreatic insulin content and morphometry}

Pancreata were removed, weighed and processed either for measurement of pancreatic insulin content or for morphometric analysis. Insulin was extracted with ethanol/acid $(0.15 \mathrm{~mol} / 1 \mathrm{HCl}$ in $75 \% \mathrm{v} / \mathrm{v}$ ethanol in water). Pancreata were placed in ice-cold fixative $(20 \mathrm{~g} / 1$ paraformaldehyde and $2 \mathrm{~g} / 1$ glutaraldehyde in $70 \mathrm{mmol} / 1$ phosphate buffered saline (PBS), $\mathrm{pH} 7 \cdot 4$ ) overnight at $4{ }^{\circ} \mathrm{C}$, followed by 4 washes at $4{ }^{\circ} \mathrm{C}$ in PBS over a 48 -h period, dehydrated in ethanol and embedded in paraffin. Pancreatic beta cell mass was calculated following immunohistochemistry for insulin on sections obtained throughout the pancreas of known weight. The area of tissue was measured in three to six different sections per animal (five animals per group: non-diabetic control (CT), streptozotocin control (STZ$\mathrm{CT}$ ), streptozotocin + oligofructose diet (STZ-OFS) and streptozotocin + restricted diet (STZ-Res)) and beta cell volume density was estimated by calculating the proportion of cells immunoreactive for insulin per sectional area of total pancreas. The beta cell volume density corresponds to the ratio of beta cell area to pancreatic parenchymal area. The beta cell mass was calculated by multiplying the beta cell volume density by the weight of the pancreas (Arany et al. 2004). 
Peptides and glucose measurement in biological samples

Glucose concentration was measured using an enzymatic procedure (Elitech Diagnostics, Brussels, Belgium). Plasma insulin was measured by ELISA (ultrasensitive rat insulinhigh range rat insulin ELISA kit, Mercodia, Uppsala, Sweden). Plasma C-peptide was measured by RIA (rat C-peptide RIA kit, Linco Research).

Extraction of GLP-1(7-36) amide from intestinal segments (ileum, caecum and colon) was carried out with ethanol/acid $(5: 1 \mathrm{v} / \mathrm{v})$ solution $(5 \mathrm{ml} / \mathrm{g}$ tissue). Samples were homogenised at top speed (24 000 r.p.m.) and kept for $24 \mathrm{~h}$ at $4{ }^{\circ} \mathrm{C}$. Homogenates were centrifuged $(2000 \mathrm{~g})$ and the supernatant was decanted and diluted in saline 200-fold for caecum and 500-fold for ileon and colon. Concentrations of GLP-1(7-36) amide were measured either in the plasma or in tissue extracts, using an ELISA method (GLP-1 active ELISA kit, Linco Research).

\section{$m R N A$ measurement}

Total RNA was isolated from each intestinal segment according to the protocol provided with the RNAgents total RNA isolation system (Promega, Leiden, The Netherlands). Briefly, approximately $250 \mathrm{mg}$ intestine were added to denaturing solution (guanidium isothiocyanate $4 \mathrm{M}$, sodium citrate $26 \mathrm{mM}$, N-lauryl sarcosine $0 \cdot 5 \%$, beta-mercaptoethanol $0 \cdot 125 \mathrm{M}$ ) and homogenised 2 times at top speed (24 000 r.p.m.) for 15 s. Sodium acetate $250 \mu \mathrm{l} 2 \mathrm{M} \mathrm{pH} \mathrm{4,} \mathrm{and} 2.5 \mathrm{ml}$ phenol:chloroform:iso-amyl alcohol (99:24:1, pH 4.7) were added to each sample. Tubes were kept for $15 \mathrm{~min}$ at $4{ }^{\circ} \mathrm{C}$ and then centrifuged at $10000 \mathrm{~g}$ for $20 \mathrm{~min}$ at $4{ }^{\circ} \mathrm{C}$. About $2.5 \mathrm{ml}$ of the RNA containing upper phase were recovered to a new centrifuge tube. An equal volume of isopropanol was added to precipitate RNA within $3 \mathrm{~h} 30 \mathrm{~min}$ at $-20^{\circ} \mathrm{C}$. Tubes were centrifuged at $10000 \mathrm{~g}$ for $15 \mathrm{~min}$ at $4{ }^{\circ} \mathrm{C}$; the supernatant was decanted and the RNA pellet was washed by adding of $2.5 \mathrm{ml}$ ice-cold $75 \%$ ethanol, and centrifuged at $10000 \mathrm{~g}$ for $15 \mathrm{~min}$ at $4{ }^{\circ} \mathrm{C}$ (2 times). The ethanol was drawn off and the pellet was diluted in $400 \mu \mathrm{l}$ RNase free water. RNA quantity and purity were determined by UV spectrophotometry at $260 \mathrm{~nm}$ and $280 \mathrm{~nm}$. Total RNA $(20 \mu \mathrm{g})$ was loaded onto agarose gel containing formaldehyde and was visualised by ethidium bromide UV light staining to check ribosomal RNA $18 \mathrm{~S}$ and $28 \mathrm{~S}$ integrity.

Proglucagon, prohormone convertase 1 (PC1) and actin $m R N A R T-P C R$ conditions

RT-PCR was performed with an input of $1 \mu \mathrm{g}$ RNA using the kit for RT-PCR (Access RT-PCR system, Promega). Primers used for the amplification of the cDNAs of interest were: forward 5'-GTAATGCTGGTA CAAGGCAG-3' and reverse 5'-TTGATGAAGTCTCT
GGTGGCA-3' for the proglucagon gene; forward 5'-GGT ACCCAAAAACTCCAGCA-3' and reverse 5'-GGCTT GTTGAGCTTTTCCAG-3' for PC1; and forward 5'-CTG ACCGAGCGTGGCTACAG-3' and reverse $5^{\prime}$-GGT GCTAGGAGCCAGGGCAG-3' for the actin gene. The 23 cycles used for the detection of the proglucagon and actin and the 35 cycles for PC1 transcripts correspond to the linear portion of the amplification curve (data not shown). PCR products ( $3 \mu \mathrm{l}$ from each) were separated on a $1.8 \%$ agarose gel in buffer Tris-acetate EDTA and were visualised by ethidium bromide UV light staining. Quantification of the PCR products was performed using the fluorimetric method using the Picogreen dsDNA quantitation reagent and kit (Molecular Probes, Leiden, The Netherlands).

\section{Statistical analysis}

Results are expressed as means \pm S.E.M. Statistical differences between groups were evaluated by analysis of variance (ANOVA) followed by Tukey honestly significant difference post hoc test using SPPS 9.0.0 for Windows (Chicago, IL, USA). The level of significance was set at $P<0 \cdot 05$.

\section{Results}

Effects of oligofructose on plasma glucose and insulin levels during oral glucose tolerance test (OGTT) in streptozotocin-treated diabetic rats

As shown in Fig. 1, oligofructose improved glucose tolerance and increased insulin levels in streptozotocintreated diabetic rats. The glucose area under the curve (AUC) was significantly lower in STZ-OFS than in STZ-CT rats, but remained higher than that measured in CT rats. Plasma insulin response to glucose during OGTT was markedly increased in STZ-OFS rats as compared with STZ-CT rats. A similar insulin AUC was measured in CT and STZ-OFS rats.

Effects of oligofructose on plasma insulin, C-peptide, pancreatic insulin content and beta cell mass in streptozotocin-treated diabetic rats

Since plasma insulin was significantly improved in STZOFS rats during the OGTT, we investigated the potential modulation of insulin production by oligofructose by measuring C-peptide, pancreatic insulin content and beta cell mass at the end of the experiment. As shown in Fig. 2A, post-prandial glycaemia of STZ-OFS rats was significantly lower than in STZ-CT rats, but remained $20 \%$ higher than in CT rats. Plasma insulin content (Fig. 2B) of STZ-OFS rats was significantly higher than STZ-CT rats, but slightly lower than the value in CT rats. 

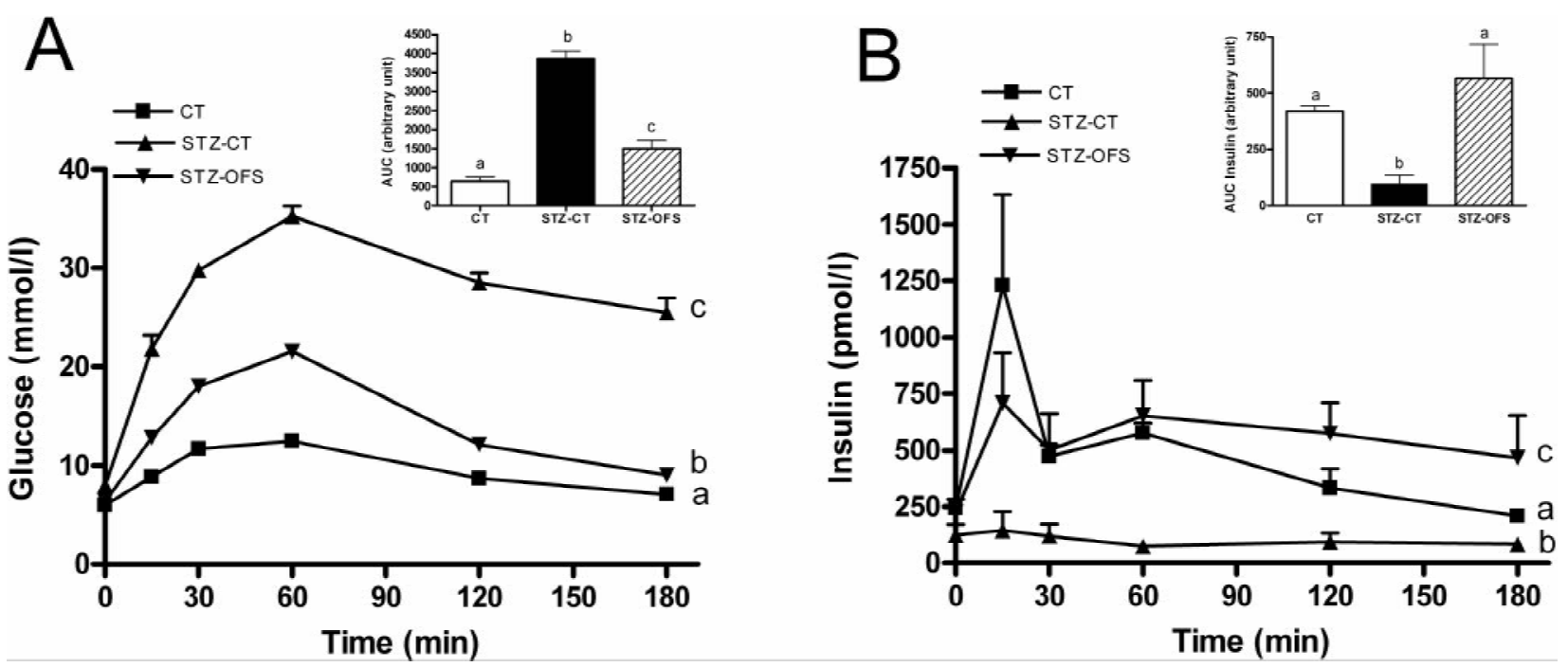

Figure 1 Effect of oligofructose on plasma levels of glucose (A) and insulin (B) during an oral glucose tolerance test in streptozotocin-treated diabetic rats performed after 4 weeks of treatment. CT and STZ-CT rats were fed a standard diet and STZ-OFS rats were fed a standard diet with $10 \%$ oligofructose. Data are means \pm S.E.M., $n=5$. Mean values with different superscript letters are significantly different, $P<0 \cdot 05$.

Plasma C-peptide content exhibited a similar profile to that of plasma insulin (Fig. 2B insert). Pancreatic insulin content (Fig. 3A) was drastically reduced in STZ-CT rats as compared with $\mathrm{CT}$ rats. However, both pancreatic insulin level and beta cell mass were about two times higher in STZ-OFS rats than in STZ-CT rats (Fig. 3B).
Effects of oligofructose on body weight gain and food consumption in streptozotocin-treated diabetic rats

At the end of the treatment, the body weight gain was 60\% lower in STZ-CT than in CT and STZ-OFS rats (Fig. 4A). From the first week following STZ treatment, the STZ-CT group presented hyperphagia which
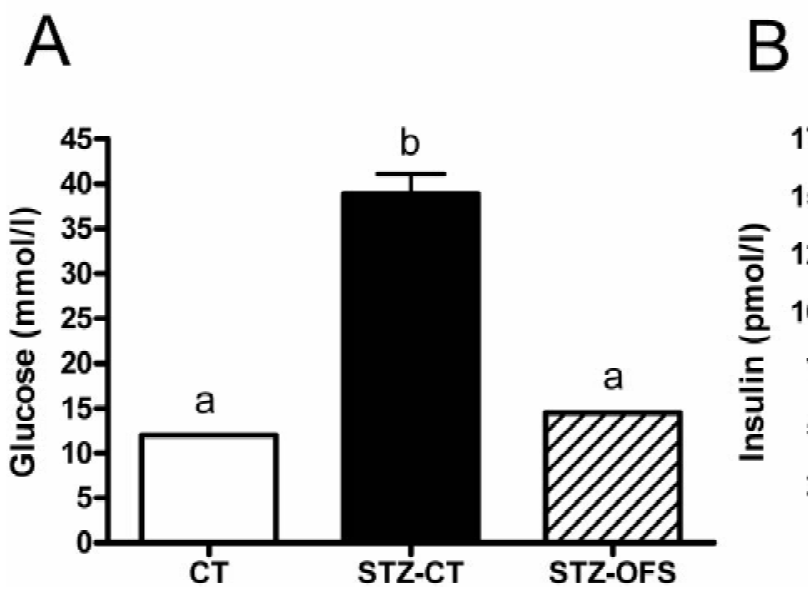

Figure 2 Effect of oligofructose on the plasma levels of glucose (A) and insulin (B) in streptozotocin-treated diabetic rats after 6 weeks of treatment. CT and STZ-CT rats were fed a standard diet and STZ-OFS rats were fed a standard diet with $10 \%$ oligofructose. Data are means \pm S.E.M., $n=5$. Mean values with different superscript letters are significantly different, $P<0.05$. 
A

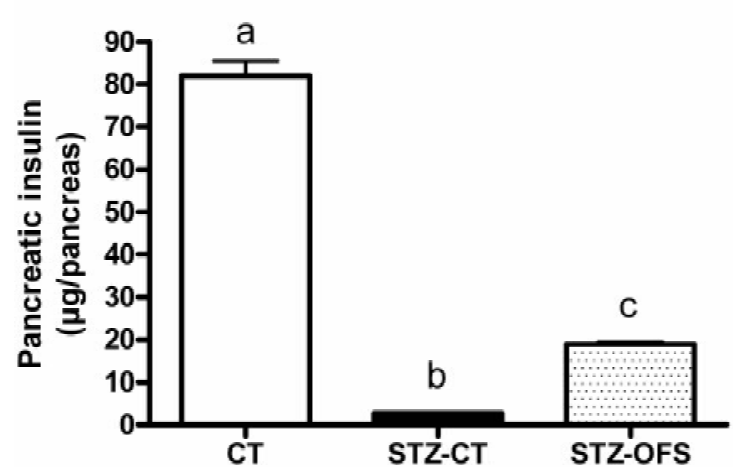

B

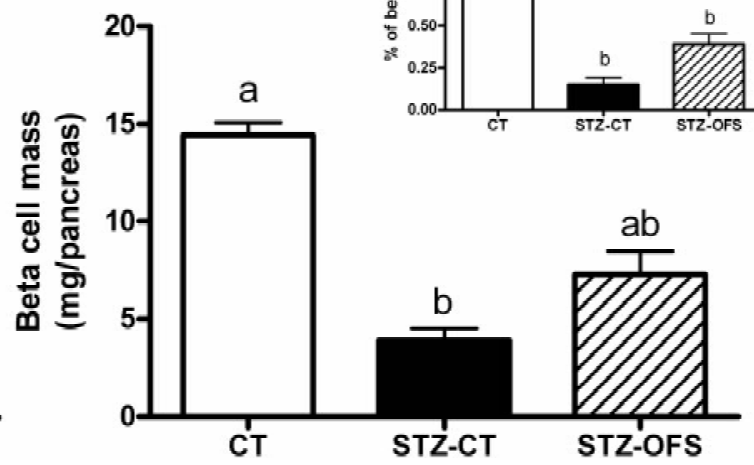

Figure 3 Effect of oligofructose on pancreatic insulin content (A) and beta cell mass (B) in streptozotocin-treated diabetic rats after 6 weeks of treatment. CT and STZ-CT rats were fed a standard diet and STZ-OFS rats were fed a standard diet with $10 \%$ oligofructose. Data are means \pm S.E.M., $n=5 ; n=4$ for beta cell mass in the STZ-OFS group. Mean values with different superscript letters are significantly different, $P<0 \cdot 05$.

remained significantly higher than in the CT group until the end of the experiment (Fig. 4B). The rats in the STZ-OFS group normalised their food consumption so as to eat the same amount as the rats in the CT group from the first week until the end of the treatment (Fig. 4B).

Effects of oligofructose on plasma portal concentrations of GLP-1(7-36) amide in streptozotocin-treated diabetic rats

Our previous studies revealed that oligofructose feeding increased plasma portal GLP-1(7-36) amide concentrations in normal rats (Cani et al. 2004). This peptide is known to improve glucose tolerance by modulating insulin secretion, beta cell mass and food intake (Drucker 2003). Since, in the present study, all these parameters were improved by oligofructose, we measured plasma portal GLP-1(7-36) amide. As shown in Fig. 5, STZ treatment induced a significant increase in portal GLP1(7-36) amide levels: the level doubled in STZ-CT as compared with CT rats. Nevertheless, STZ-OFS rats exhibited a more marked increase in portal GLP-1(7-36) amide levels, reaching four times the CT value. Thus, we confirmed that oligofructose feeding increases plasma portal GLP-1(7-36) amide.

\section{Effect of oligofructose and food restriction on beta cell mass}

We performed a second set of experiments in order to identify the influence of the specific effect of oligofructose on the modulation of GLP-1(7-36) amide production versus food restriction in streptozotocin-treated diabetic rats.

We confirmed that beta cell mass was about two times higher in STZ-OFS rats than in STZ-CT rats and that food restriction did not influence beta cell mass
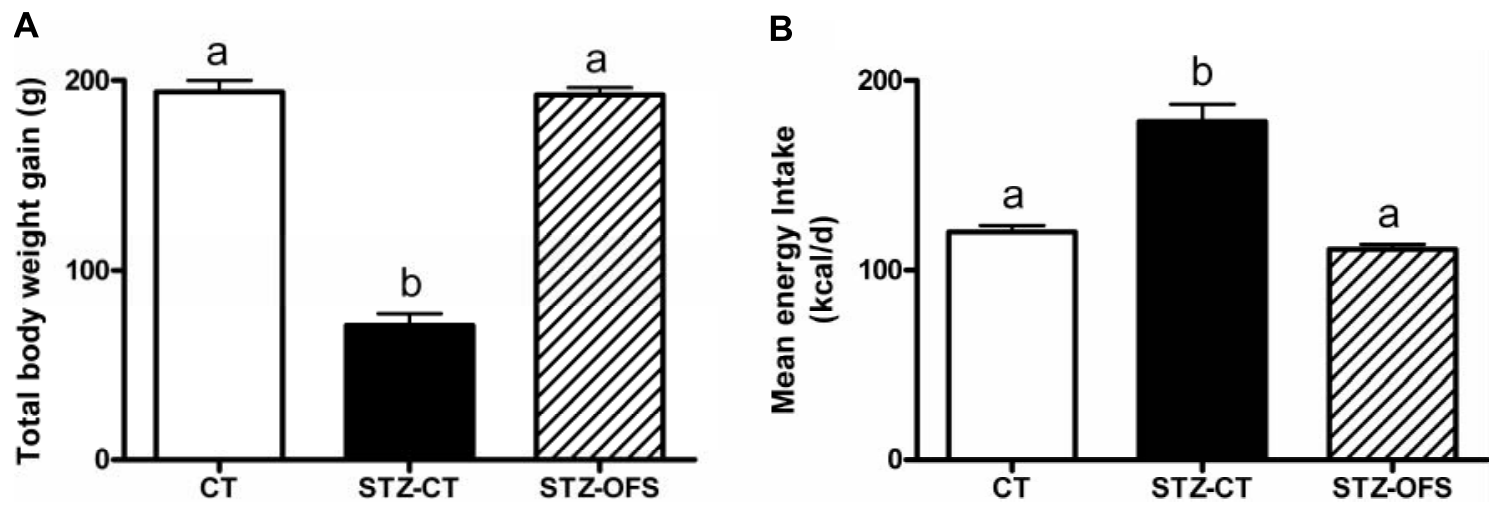

Figure 4 Effect of oligofructose on body weight (A) and energy intake (B) in streptozotocin-treated diabetic rats after 6 weeks of treatment. CT and STZ-CT rats were fed a standard diet and STZ-OFS rats were fed a standard diet with $10 \%$ oligofructose. Data are means \pm S.E.M., $n=5$. Mean values with different superscript letters are significantly different, $P<0 \cdot 05$. 


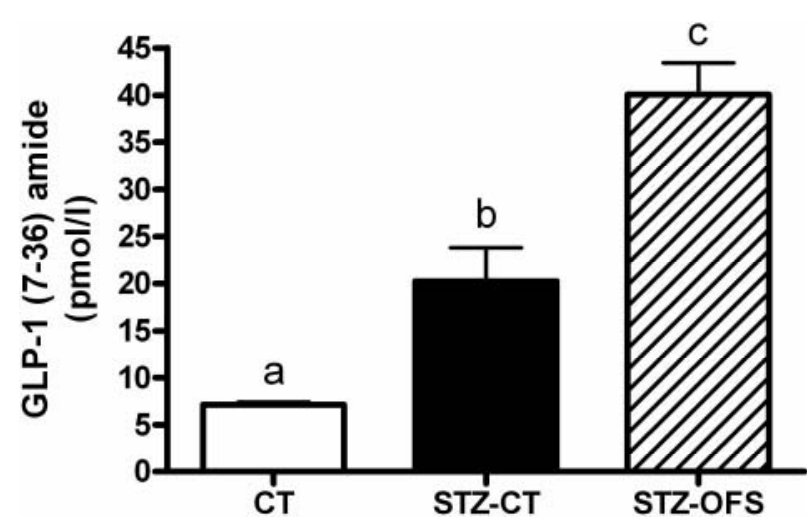

Figure 5 Effect of oligofructose on plasma portal vein GLP-1(7-36) amide content in streptozotocin-diabetic rats after 6 weeks of treatment. CT and STZ-CT rats were fed a standard diet and STZ-OFS rats were fed a standard diet with $10 \%$ oligofructose. Data are means \pm S.E.M., $n=5$. Mean values with different superscript letters are significantly different, $P<0 \cdot 05$.

(mg/pancreas: CT $7 \cdot 97 \pm 1 \cdot 37^{\mathrm{a}}$, STZ-CT $0 \cdot 59 \pm 0 \cdot 16^{\mathrm{b}}$, STZ-OFS $1.46 \pm 0.57^{\mathrm{b}}$, STZ-Res $0.55 \pm 0.21^{\mathrm{b}}$; \% of beta cell mass: CT $0.85 \pm 0 \cdot 14^{\mathrm{a}}$, STZ-CT $0.08 \pm 0.03^{\mathrm{b}}$, STZ-OFS $0.17 \pm 0.06^{\mathrm{b}}$, STZ-Res $0.06 \pm 0.02^{\mathrm{b}}$; mean values with different superscript letters were significantly different, $P<0 \cdot 05)$. Histological analysis confirmed these results. STZ-CT and STZ-Res rats exhibited a lower number and size of Langerhans islets than CT rats, and also included a lot of necrotic cells. In the pancreatic tissue of STZ-OFS rats, the alterations were more discrete, the number and the size of Langerhans islets being higher than those observed in STZ-CT rats (data not shown).

Effect of oligofructose and food restriction on portal and intestinal GLP-1(7-36) amide content in streptozotocin-treated diabetic rats

Figure 6A shows that STZ-Res rats exhibited a similar plasma portal GLP-1(7-36) amide concentration as CT rats. Levels of plasma portal GLP-1(7-36) amide were two times higher in STZ-CT than in CT rats, and four times higher in STZ-OFS than in CT rats. GLP-1(7-36) amide is produced by L-cells (mainly located in the ileon and colon) from posttranslational processing of proglucagon by the PC1 enzyme. Therefore, GLP-1(7-36) amide, proglucagon and PC1 mRNA levels were measured in these intestinal segments.

As shown in Fig. 6B, ileal GLP-1(7-36) amide concentration was slightly increased $(30 \%)$ in STZ-CT rats compared with CT rats; this phenomenon did not occur in STZ-OFS and in STZ-Res rats. A major and significant increase (by about threefold) in GLP-1(7-36) amide concentration was observed in the colonic tissue of STZOFS rats. Proglucagon mRNA in the different intestinal segments was similar in CT and STZ-CT rats, whereas
A

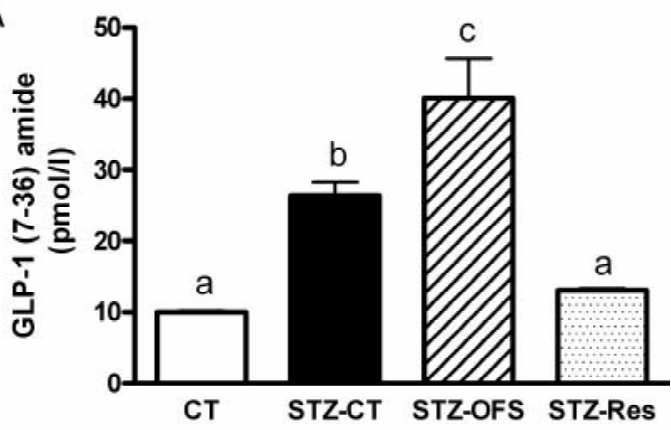

B
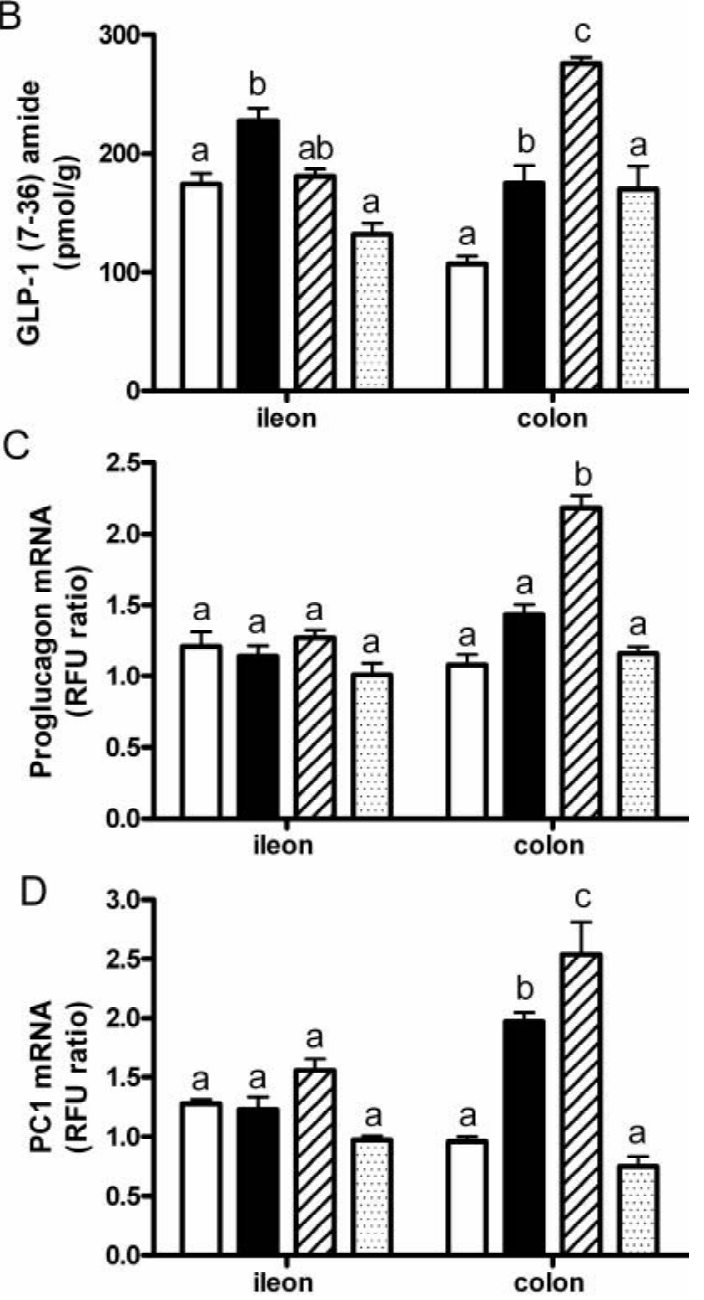

Figure 6 Effect of oligofructose and food restriction on the levels of GLP-1(7-36) amide in the portal vein (A) and the intestinal segment (B), and on the levels of proglucagon (C) and PC1 mRNA (D). CT and STZ-CT rats were fed a standard diet and STZ-OFS rats were fed a standard diet with $10 \%$ oligofructose. STZ-Res rats were food restricted so as to receive the same amount of food as the $\mathrm{CT}$ rats. RFU ratio, relative fluorescence units ratio of proglucagon or PC1 mRNA/beta actin mRNA. Data are means \pm S.E.M., $n=5$. Mean values with different superscript letters are significantly different, $P<0 \cdot 05$. Open bars, non-diabetic CT group; solid bars, STZ-CT group; hatched bars, STZ-OFS group; stippled bars, STZ-Res group. 
PC1 mRNA was increased twofold in the colonic tissue of STZ-CT compared with CT rats. This effect was not observed in food-restricted rats. OFS treatment increased colonic proglucagon mRNA and PC1 mRNA by about 2 - and 2.5-fold respectively compared with CT rats (Fig. 6C,D). Food restriction abolished all the effects of STZ treatment on intestinal GLP-1 synthesis.

\section{Discussion}

In the present paper, we report an interesting effect of dietary oligofructose on glucose homeostasis in STZtreated diabetic rats: the addition of oligofructose at a dose of $10 \%$ for 4 weeks in the diet of rats improves glycaemia and plasma insulin, both in the post-prandial state and after an oral glucose load. Moreover, the treatment with oligofructose allows an improvement of pancreatic insulin and beta cell mass which was observed after 6 weeks of treatment. The influence of OFS on glucose metabolism and satiety might not be attributed to a gel-forming or viscous effect, as suggested for other dietary fibres (Nuttall 1993). Another mechanism can be proposed: an increasing number of papers demonstrates a key role of GLP-1(7-36) amide, secreted by the L-cells of intestinal tissue, on the control of glucose homeostasis and pancreatic beta cell function (increased insulin secretion, beta cell neogenesis, ...) on the one hand, and food intake on the other (Turton et al. 1996, Drucker 2003). Our previous studies revealed that oligofructose feeding doubled the level of plasma portal GLP-1(7-36) amide in normal rats (Cani et al. 2004). In the present study, plasma portal GLP-1 (7-36) amide was increased fourfold in STZ-OFS rats as compared with controls. Thus GLP-1(7-36) amide overproduction might be part of the protective and hypoglycaemic effect of dietary fructans. Such a mechanism has been proposed to explain the effectiveness of guar gum in improving hyperglycaemia in hyperphagic diabetic rats (Cameron-Smith et al. 1997). In the present study, oligofructose effects were related to a reduced food intake. Thus, we cannot exclude the possibility that the satietogenic effect of OFS could be involved in the improvement of glucose and pancreatic parameters. Therefore, in a second experiment, we decided to study the putative modulation of intestinal GLP-1(7-36) amide production, and then to investigate the putative effect of food restriction on beta cell pancreatic function.

Surprisingly, we show here that the diabetic state per se correlates with an increase in GLP-1(7-36) amide content observed in the intestinal portions of STZ-CT rats and, more specifically, in the ileon. Nie et al. (2000) have shown that PC1 expression is increased in pancreatic alpha cells of rats which have received several i.p. injections of STZ. This phenomenon is correlated with a higher pancreatic GLP-1(7-36) amide content (Nie et al. 2000). Our results indicate that the higher ileal GLP-1(7-36) amide concentration observed in STZ-CT rats may not be attributed to proglucagon or PC1 overexpression. The ileal overproduction of GLP-1(7-36) amide in STZ-treated diabetic rats is clearly linked to hyperphagia since it is prevented in both food-restricted and STZ-OFS animals.

In this protocol, we demonstrate that OFS treatment has the same effect in diabetic rats as that previously observed in normal rats: it produces an increase in GLP-1(7-36) amide in the colon with consequences on its level in the portal vein (Cani et al. 2003, 2004). But what is the mechanism? Although data are scare, there are a few papers that suggest that dietary fibres (rhubarb fibre, fermentable dietary fibres) may promote colon proglucagon expression and GLP-1(7-36) amide production in rats and dogs (Reimer \& McBurney 1996, Reimer et al. 1997, Massimino et al. 1998). The increase in colonic GLP-1(736) amide after OFS treatment occurs together with higher levels of proglucagon and PC1 mRNA. The link between OFS feeding and proglucagon and PC1 gene expression in L cells is plausible, since the SCFA (such as acetate, propionate, butyrate) produced in the caecocolon through the fermentation of fructans are involved in GLP-1(7-36) amide synthesis. The direct colonic instillation or systemic administration of a mix of SCFA increases proglucagon mRNA (Tappenden et al. 1996, 1998, Tappenden \& McBurney 1998). Butyrate, which is overproduced in the caeco-colon of oligofructose-treated rats (Le Blay et al. 1999), seems to be the more potent among SCFA in the modulation of proglucagon gene expression; the molecular mechanism would involve an increase in caudal family homeobox protein $\mathrm{cdx}-2$ expression, a transcription factor known to activate the rat proglucagon gene promoter (Jin \& Drucker 1996, Domon-Dell et al. 2002).

The results obtained in the STZ-Res group, which had a 'more severe' food restriction than the STZ-OFS group, allows us to draw two conclusions: (1) the higher GLP-1 synthesis in STZ-CT rats is clearly linked to hyperphagia, since it is avoided by a drastic caloric restriction and (2) the beneficial effect of OFS is not due to food restriction only, since the improvement of pancreatic beta cell mass is observed in the STZ-OFS group and not in the STZ-Res group.

The modulation of colonic GLP-1(7-36) amide production by oligofructose in diabetic rats allows a fourfold increase in the portal concentration of GLP-1(7-36) amide, the portal vein being considered as the key biological compartment in which this peptide acts to regulate glucose homeostasis (Burcelin et al. 2001). Several studies report the interest in oligofructose as a means of lowering glycaemia in various animal models (Kok et al. 1998b, Daubioul et al. 2000). However, Perrin et al. (2003) have recently reported that oligofructose, given at a dose of $5 \%$ in diabetes-prone BioBreeding (BB) rats, was unable to modulate colonic mucosa and, consequently, could not counteract protein-induced hyperglycaemia in this model. 
The authors suggested that the effects of fermentable fibres on the intestine are important in allowing them to play a regulatory role. We propose that the capacity of oligofructose to modulate L-cells-derived GLP-1 synthesis is an important factor which must be taken into account in the interpretation of the physiological effect on satiety and glucose metabolism. Peptides other than GLP-1, such as peptide $\mathrm{YY}$, are also increased in intestinal tissue and portal veins of oligofructose-fed non-diabetic animals, this phenomenon being accompanied by lower serum ghrelin levels (Cani et al. 2004).

The relevance of the effect of fructans on levels of GLP-1(7-36) amide, glycaemia and satiety in humans is only poorly documented. An increase in serum GLP-1 (7-36) amide was already shown in patients presenting with gastro-intestinal reflux, who received $3 \times 6.6 \mathrm{~g} /$ day oligofructose in their diet for 7 days, thus suggesting that the promotion of GLP-1(7-36) amide secretion may occur in humans despite the much lower intake of oligofructose/ day as compared with rat studies (Piche et al. 2003). On the other hand, a decrease in glycaemia appears during fructans treatment in moderately hyperglycaemic patients (Yamashita et al. 1984).

In conclusion, dietary oligofructose, through their fermentation in the colon, promote the secretion of intestinal peptides, a phenomenon contributing to improved glucose homeostasis and a normalisation of the high food intake which is characteristic of streptozotocintreated diabetic rats. Our results suggest that dietary fibre, which exhibits a high fermentation in the gut, might be proposed as a nutritional adjuvant in the management of diabetes, based on the endogenous promotion of incretin peptides secretion by the colon.

\section{Acknowledgements}

The authors thank N Maton for her technical assistance. C A Daubioul was financed by a Danone Institute Research Grant. P D Cani is a teaching assistant at the Université catholique de Louvain. This work was supported by an FSR grant from the Université catholique de Louvain. Oligofructose was kindly provided by ORAFTI. The authors declare that there is no conflict of interest that would prejudice the impartiality of this scientific work.

\section{References}

Arany E, Strutt B, Romanus P, Remacle C, Reusens B \& Hill DJ 2004 Taurine supplement in early life altered islet morphology, decreased insulinitis and delayed the onset of diabetes in non-obese diabetic mice. Diabetologia 47 1831-1837.

Burcelin R, Da Costa A, Drucker D \& Thorens B 2001 Glucose competence of the hepatoportal vein sensor requires the presence of an activated glucagon-like peptide-1 receptor. Diabetes $\mathbf{5 0}$ $1720-1728$.
Busserolles J, Gueux E, Rock E, Demigne C, Mazur A \& Rayssiguier Y 2003 Oligofructose protects against the hypertriglyceridemic and pro-oxidative effects of a high fructose diet in rats. Journal of Nutrition 133 1903-1908.

Cameron-Smith D, Habito R, Barnett M \& Collier GR 1997 Dietary guar gum improves insulin sensitivity in streptozotocin-induced diabetic rats. Journal of Nutrition 127 359-364.

Cani PD, Neyrinck A, Dewever C, Daubioul C \& Delzenne NM 2003 Dietary fermentable fructooligosaccharide modulates gastro-intestinal peptides involved in appetite regulation (glucagon-like peptide-1 and ghrelin) in rats. Annals of Nutrition and Metabolism 47 395-396 (Abstract).

Cani PD, Dewever C \& Delzenne NM 2004 Inulin-type fructans modulate gastro-intestinal peptides involved in appetite regulation - glucagon-like peptide-1 and ghrelin - in rats. British Journal of Nutrition 92 521-526.

Daubioul CA, Taper HS, De Wispelaere LD \& Delzenne NM 2000 Dietary oligofructose lessens hepatic steatosis, but does not prevent hypertriglyceridemia in obese zucker rats. Journal of Nutrition $\mathbf{1 3 0}$ 1314-1319.

Daubioul C, Rousseau N, Demeure R, Gallez B, Taper H, Declerck B \& Delzenne N 2002 Dietary fructans, but not cellulose, decrease triglyceride accumulation in the liver of obese Zucker fa/fa rats. Journal of Nutrition 132 967-973.

Delzenne NM 2003 Oligosaccharides: state of the art. Proceedings of the Nutrition Society 62 177-182.

Delzenne NM \& Williams CM 2002 Prebiotics and lipid metabolism. Current Opinion in Lipidology 13 61-67.

Delzenne N, Cherbut C \& Neyrinck A 2003 Prebiotics: actual and potential effects in inflammatory and malignant colonic diseases. Current Opinion in Clinical Nutrition and Metabolic Care 6 581-586.

Domon-Dell C, Wang Q, Kim S, Kedinger M, Evers BM \& Freund JN 2002 Stimulation of the intestinal Cdx2 homeobox gene by butyrate in colon cancer cells. Gut 50 525-529.

Drucker DJ 2002 Biological actions and therapeutic potential of the glucagon-like peptides. Gastroenterology Review 122 531-544.

Drucker DJ 2003 Glucagon-like peptides: regulators of cell proliferation, differentiation, and apoptosis. Molecular Endocrinology Review 17 161-171.

Jenkins DJA, Kendall CWC \& Vuksan V 1999 Inulin, oligofructose and intestinal function. Journal of Nutrition 129 S1431-S1433.

Jin T \& Drucker DJ 1996 Activation of proglucagon gene transcription through a novel promoter element by the caudal-related homeodomain protein $\mathrm{cdx}-2 / 3$. Molecular and Cellular Biology 16 19-28.

Kok NN, Taper HS \& Delzenne NM 1998a Oligofructose modulates lipid metabolism alterations induced by a fat-rich diet in rats. Journal of Applied Toxicology 18 47-53.

Kok NN, Morgan LM, Williams CM, Roberfroid MB, Thissen JP \& Delzenne NM 1998b Insulin, glucagon-like peptide 1, glucose-dependent insulinotropic polypeptide and insulin-like growth factor I as putative of the hypolipidemic effect of oligofructose in rats. Journal of Nutrition 128 1099-1103.

Le Blay G, Michel C, Blottiere HM \& Cherbut C 1999 Prolonged intake of fructo-oligosaccharides induces a short-term elevation of lactic acid-producing bacteria and a persistent increase in caecal butyrate in rats. Journal of Nutrition 129 2231-2235.

Massimino SP, McBurney MI, Field CJ, Thomson AB, Keelan M, Hayek MG \& Sunvold GD 1998 Fermentable dietary fiber increases GLP-1 secretion and improves glucose homeostasis despite increased intestinal glucose transport capacity in healthy dogs. Journal of Nutrition 128 1786-1793.

Nie Y, Nakashima M, Brubaker PL, Li QL, Perfetti R, Jansen E, Zambre Y, Pipeleers D \& Friedman TC 2000 Regulation of pancreatic PC1 and PC2 associated with increased glucagon-like peptide 1 in diabetic rats. Journal of Clinical Investigation 105 955-965. 
Nuttall FQ 1993 Dietary fibre in the management of diabetes. Diabetes Review 42 503-508.

Orskov C, Bersani M, Johnsen AH, Hojrup P \& Holst JJ 1989 Complete sequences of glucagon-like peptide-1 from human and pig small intestine. Journal of Biological Chemistry 264 12826-12829.

Perrin IV, Marchesini M, Rochat FC, Schiffrin EJ \& Schilter B 2003 Oligofructose does not affect the development of type 1 diabetes mellitus induced by dietary proteins in the diabetes-prone BB rat model. Diabetes, Nutrition and Metabolism 16 94-101.

Piche T, des Varannes SB, Sacher-Huvelin S, Holst JJ, Cuber JC \& Galmiche JP 2003 Colonic fermentation influences lower esophageal sphincter function in gastroesophageal reflux disease. Gastroenterology 124 894-902.

Reimer RA \& McBurney MI 1996 Dietary fiber modulates intestinal proglucagon messenger ribonucleic acid and postprandial secretion of glucagon-like peptide-1 and insulin in rats. Endocrinology 137 3948-3956.

Reimer RA, Thomson AB, Rajotte RV, Basu TK, Ooraikul B \& McBurney MI 1997 A physiological level of rhubarb fiber increases proglucagon gene expression and modulates intestinal glucose uptake in rats. Journal of Nutrition 127 1923-1928.

Roberfroid MB \& Delzenne NM 1998 Dietary fructans. Annual Reviews of Nutrition 18 117-143.

Tappenden KA \& McBurney MI 1998 Systemic short-chain fatty acids rapidly alter gastrointestinal structure, function, and expression of early response genes. Digestive Diseases and Sciences 43 $1526-1536$.

Tappenden KA, Thomson AB, Wild GE \& McBurney MI 1996 Short-chain fatty acids increase proglucagon and ornithine decarboxylase messenger RNAs after intestinal resection in rats. Journal of Parenteral and Enteral Nutrition 20 357-362.

Tappenden KA, Drozdowski LA, Thomson AB \& McBurney MI 1998 Short-chain fatty acid-supplemented total parenteral nutrition alters intestinal structure, glucose transporter 2 (GLUT2) mRNA and protein, and proglucagon mRNA abundance in normal rats. Amercian Journal of Clinical Nutrition 68 118-125.

Turton MD, O'Shea D, Gunn I, Beak SA, Edwards CM, Meeran K, Choi SJ, Taylor GM, Heath MM, Lambert PD et al. 1996 A role for glucagon-like peptide-1 in the central regulation of feeding. Nature 379 69-72.

Yamashita K, Kawai K \& Itakura M 1984 Effects of fructo-oligosaccharides on blood glucose and serum lipids in diabetic subjects. Nutrition Research 4 961-966.

Received 1 March 2005

Accepted 4 March 2005

Made available online as an

Accepted Preprint 10 March 2005 